\title{
Anomie in the Oil Patch: A Preliminary Analysis
}

F. Matt Jones

School of Criminal Justice

University of Central Oklahoma

100 North University Drive

Edmond, Oklahoma 73034

Corresponding author: F. Matt Jones, fredmatthewjones@gmail.com

\begin{abstract}
This article explores the relationship between rising rates of violent crime and suicide in the oil producing region of western North Dakota during a time of rapid expansion for the oil extraction industry. The objectives of this article are: (1) to introduce the preliminary findings of a larger study that examines the rising rates of crime and other social problems within the socioeconomic context that currently exists in the oil extracting regions of western North Dakota; and (2) on a theoretical level, Durkheim's theory of anomie is discussed and proposed as an explanation for the rising rates of crime and suicide that have accompanied the growing oil industry.
\end{abstract}

Keywords: anomie, boomtowns, Durkheim, violent crime, suicide 


\section{Introduction}

This article is an exploratory effort investigating the rates of crime and suicide in the oil producing region of western North Dakota during a time of rapid expansion for the oil extraction industry. The objectives of this article are: (1) to introduce some of the preliminary findings of a larger study that examines the rising rates of violent crime and other social problems within the socioeconomic context that currently exists in the oil extracting regions of western North Dakota; and (2) on a theoretical level Durkheim's theory of anomie is discussed and proposed as an explanation for the rising rates of crime and other social problems which appear to have accompanied the growing oil industry.

The recent rapid increase in oil production in western North Dakota has garnered a great deal of attention on the national level. However, the production of oil is not the only thing drawing attention to region. Rising crime rates and an increase in a number of social ills have accompanied the prosperity of oil production. Concerns over rising crime rates, child abuse and neglect, suicide and other ills have followed along with the economic prosperity and are often neglected by industry and governmental agencies. The neglect of social ills is not unique to the current boom in the Bakken region, similar findings have been reported in previous booms (Little 1976) and other regions (O’Connor 2012; 2014). Davenport III and Davenport (1980) define a boomtown as: (1) A community experiencing above average economic and population growth; (2) which results in benefits for the community, e.g. expanded tax base, increased employment opportunities, social and cultural diversity; and (3) but which also places or results in strain on existing community and societal institutions, e.g. familial, economic, educational, legal and political (p.43).

Since Kohrs (1974), the boomtown phenomenon associated with the energy extraction industry in the United States and Canada has garnered the attention of scholars; however, some scholars maintain research pertaining to the social costs of these boomtowns has been lacking (Goldenberg, Shoveller, Koehoorn and Ostry 2008) and that when environmental impact surveys are conducted they often ignore or mitigate social issues in favor of economic incentives (Carrington, Hogg and McIntosh 2011; Little 1976). This study examines changes in rates of violent crime and suicide in the Bakken region ${ }^{1}$.

This article begins with a brief synopsis of Durkheim's theory of anomie as discussed in The Division of Labor in Society ([1893]1984) and Suicide ([1897]1951). A brief review of empirical assessments of Durkheim's theory concerning violent crime and suicide follows, then pertinent findings from boomtown literature are presented. Next, preliminary findings are presented, then connections between these findings and Durkheim's anomie are drawn in the discussion and summary section. 


\section{Durkheim's Anomie}

Emile Durkheim serves as one of the seminal contributors to the field of sociology; his contributions to criminology are numerous as well. Many authors consider Durkheim's concept of anomie to be his most important contribution to the field of criminology (Mannheim 1972). The concept, in one form or another, is reflected in not only the $20^{\text {th }}$ century anomie theories but also other theories in the field (e.g. social disorganization and social control). Durkheim introduced the term "anomie" in The Division of Labor in Society ([1893]1984) and soon after used it extensively in Suicide ([1897]1951). Though Durkheim portrays anomie in multiple ways, it is deregulation which serves as a constant feature of anomie in his writings. More specifically it is the lack, weakening or lagging of regulatory mechanisms in societies which result in episodes of anomie.

This section serves as a brief synopsis of Durkheim's theory of anomie as presented in The Division of Labor and Suicide. The first section discusses Durkheim's theory of anomie as presented in Book III of The Division of Labor; the next section presents anomie as discussed in Suicide; following that section are Durkheim's thoughts on anomie from the preface of the second edition of The Division of Labor.

\section{Anomie in The Division of Labor in Society}

Before utilizing Durkheim's notion of anomie to account for the increased rates of crime and social ills experienced by the populace in the rapidly changing regions of the Bakken, it is important to address the differing uses of the term anomie by Durkheim himself. As mentioned above, Durkheim introduced the notion of anomie in The Division of Labor ([1893]1984). Durkheim argues as society evolves the collective consciousness ${ }^{2}$ weakens due to the development of differing sentiments among groups; these differing sentiments result from the increasing specialization ${ }^{3}$ of group members. The division of labor organizes the evolving specializations and replaces shared sentiments of "simpler societies" as the source of solidarity.

According to Durkheim, at first glance the critical function of the division of labor appears to be to "improve both productive capacity and skill of the workman" (p. 12); however, this belief is both shortsighted and superficial. The division of labor's "true function is to create between two or more people a feeling of solidarity" (p. 17). In fact Durkheim maintains, "the economic services that it can render are insignificant compared with the moral effect that it produces" (p. 17). The division of labor results in complimentary differences between groups producing solidarity through mutual dependence. By organizing differing specializations into a state of mutual dependence, "different occupations can co-exist without being forced into a position where they harm one another, for they are pursuing different objectives" (p. 209), and "each one of them can therefore reach his goal without preventing others from reaching theirs" 
(p. 209). The division of labor's most "notable effect is not that it increases the productivity of the functions that are divided in this way, but that it links them very closely together" (p. 21). It is this effect that Durkheim views as the ultimate role of the division of labor, i.e. solidarity not productivity. The influence of the division of labor is far reaching outside of "economic interests, for it constitutes the establishment of a social and moral order sui generis" (p. 21).

Durkheim believes what the division of labor "evokes are functions, that is, definite ways of acting that are repeated identically in given circumstances" (p. 302) producing the scripts which regulate social interactions. However, he also discusses circumstances in which the division of labor does not produce solidarity because it emerges in an "abnormal form", one of which is the anomic division of labor. In this case, "the division of labor does not produce solidarity because the relations between the organs are not regulated; ... they are in a state of anomie" (p. 304). It is during periods of anomie that "incoherency", "disorder" and "disintegration" are likely to occur. When the division of labor is anomic, the scripts that guide interactions have lost their regulatory power, often times due to some lag between the collective consciousness and new conditions caused by some rapid social change.

While any social arena may face episodes of anomie, Durkheim believed the sectors of business and industry were especially susceptible to this phenomenon. An anomic division of labor may arise when rapid industrialization occurs and with it, new conditions of economic life that "naturally require a new organization" (p. 306). He continues, "because these transformations have been accomplished with extreme rapidity the conflicting interests have not had time to strike an equilibrium" (p. 306). The scripts provided by the division of labor are produced only after ample repetition. Where such repetition is absent, it can only "unite individuals for a brief space of time ... it could not give rise to any regulatory process" (p. 302). This lagging behind of regulatory practices and institutions is a principal source of anomie affirmed by Durkheim.

Another source of anomie addressed is the rapid expansion of a market. In his discussion concerning the progression of markets, Durkheim argued that when a branch of industry fails to coordinate its level of production with the corresponding level of consumption, "this lack of regulation does not allow the functions to perform regularly and harmoniously" (p. 303). Following this logic, an immeasurable market, such as an international market (p. 305), is "so to speak, unlimited. Consequently, production lacks any check or regulation" (p. 305). In such a market, production "can only proceed at random" lacking any governance (p. 305); the lack of regulation in such a market represents another dimension of anomie.

While there are multiple sources of an anomic division of labor, Durkheim's focal point regarding his theory of anomie in The Division of Labor centers on the regulation of interactions between different groups or "organs" that constitute society. By organizing specializations, the 
division of labor produces scripts that regulate the interactions within a society. When these scripts lose their regulatory authority, often times due to some cultural lag between the collective consciousness and new social conditions, the interactions between different societal groups are inclined to fall into a state of deregulation that is anomie. For instance, due to the rapid progression of industry, society may be unable to provide any counter regulatory mechanism.

\section{Anomie in Suicide}

In Suicide Durkheim ([1897]1951) again utilizes the theory of anomie as an explanation for societal unrest that contributes to increased social disorder. In The Division of Labor anomie is described as a lack of regulation involving the interactions of different "organs" of society; however, in Suicide anomie results from the inability of a society to regulate the desires of its members. While deregulation remains the crux of anomie in both works, what is being regulated constitutes the major difference between these uses of the term. To understand why it is critical for a larger "moral force" to regulate the desires of a populace, a brief discussion of Durkheim's views concerning human nature is necessary.

In a word, Durkheim's conception of human nature may be considered somewhat grim. According to the assessment conveyed in Suicide, Durkheim believes human desire is an "insatiable and bottomless pit" (p. 247) that "aspires beyond assignable limits and sets unattainable goals" (p. 248). Therefore, human nature needs to be regulated by some force "superior" and "external" to the individual. The force to which Durkheim is alluding is society. According to Durkheim, human nature will lead only to "torment" and disappointment if left to its own inclination. Even when a goal is achieved, this satisfaction only "stimulates instead of filling needs" (p. 248), causing any feelings of satisfaction or achievement to contribute to the "inextinguishable thirst" that is a "constantly renewed torture" (p. 248).

It is for these reasons that we require some external force to place a lid on the unattainable desires to which we are naturally inclined, according to Durkheim. As briefly mentioned earlier, "society can play this moderating role; for it is the only moral power superior to the individual, the authority of which he accepts" (p. 249). When society is able to regulate its members, "an end goal is set to the passions" (p. 250). Society can serve to ensure that man's "needs are sufficiently proportioned to his means" (p. 246), by providing limits to desires. Though not "legally formulated", society exerts its "collective authority", an authority that "fixes with relative precision the maximum degree of ease of living to which each social class may legitimately aspire" (p. 249) and therefore places a practical limit on the aspirations of societal members. This is not to say that Durkheim supported a caste system wherein members of different classes were disallowed to improve their lot in life; rather, this restraint would allow for men to be "content with their lot while stimulating them moderately to improve it" (p. 250). From this restraint and gratification would result a culture of "calm, active happiness, the 
pleasure in existing and living which characterizes health for societies as well as for individuals" (p. 250). Durkheim believed with proper regulation society is able to compel people to focus on what they have; rather than allowing their infinite desires to pine for what they do not have.

As Durkheim frequently noted, there are "disturbances of the collective order" (e.g. rapid industrialization) that result in periods of decreased regulation in society and, thus heightened states of anomie (p. 246). According to Durkheim, during these times society suffers from a multitude of social ills and "men are more inclined to self-destruction" (p. 246). Disruptions of the collective order may occur anytime "society is disturbed by some painful crisis or by beneficent but abrupt transition" (p. 252). When such an unanticipated transformation occurs in society, regulations often lag behind the change, as described earlier. They are rendered ineffective not only in guiding social interactions but also in placing limits on the goals and desires of society's members. While such disruptions can result from multiple causes, in Suicide Durkheim again targets economic change as a crucial catalyst of anomie.

Though Durkheim briefly addresses the role of "economic disasters" as a source of anomie, he devotes more attention to the effects of "abrupt growth of power and wealth" (p. 253) bred by rapid economic growth. Durkheim points to the development of industry and the goal of "achieving industrial prosperity" (p. 255) as a source of deregulation. This deregulation serves to enhance a reciprocal relationship involving increased rates of prosperity, market expansion and human desires that heighten anomic tendencies in the economic sphere. It also forces other institutions that previously had some regulatory influence into positions of subservience to the pursuit of larger and richer markets. Where religion and government used to serve as regulating forces, Durkheim holds that they now serve only as "tools and servants" of industry. ${ }^{4}$ Under these conditions, "all regulation is lacking ...the limits are unknown between the possible and impossible, what is just and what is unjust" (p. 253). Durkheim believed these conditions were "chronic" in the "sphere of trade and industry" in late $19^{\text {th }}$ century France (p.254). Until society is able to restore some restraint to human desires, anomie will persist. However, given time Durkheim believed such regulation should eventually develop.

When anomie becomes chronic, unlimited desires are so common that "society has grown to accept them and is accustomed to think them normal" (p. 257). For this reason, society assimilates the anomic tendencies of industry into other areas of social life (p. 256). This expansion to other areas of social life has slowed the development of future regulatory efforts. In fact, Durkheim suggests any application of restraint "seems like some sort of sacrilege" (p.255). Due to the infiltration of the modern economy into other parts of social life, "the doctrine of the most ruthless and swift progress has become an article of faith" (p. 257) not only for trade and industry, as well for other spheres of social life. 
While Durkheim devotes the majority of his attention to anomie's effect on suicide rates, he briefly, though directly, addresses the possible effects of anomie on homicide. Durkheim believes that anomie produces in individuals "a state of exasperation and irritated weariness" ( $p$. 357). Not only does anomie affect the individual by producing these feelings, these feelings "may turn against the person himself or another according to circumstances; in the first case we have suicide, in the second, homicide" (p. 357). Durkheim concludes the same anomic conditions that increase suicide rates also increase homicide rates, thus anomie is viewed as one cause of homicide.

\section{Anomie in the Preface to the $2^{\text {nd }}$ edition of The Division of Labor in Society}

In the preface to the $2^{\text {nd }}$ edition of The Division of Labor in Society ([1902]1984), Durkheim's attention remains focused on the chronic state of anomie he believes to exist in the economic sphere of late-nineteenth century societies. Nearly a decade after the publication of the first edition of The Division of Labor, Durkheim held that anomic conditions continued to plague society; accordingly, it is to this "chronic state" of anomie that "must be attributed the continually recurring conflicts and disorders of every kind of which the economic world affords so sorry a spectacle" (p. xxxii). This chronic state of anomie has inhibited the creation of "professional ethics" and because of this the pursuit of "success" has forced many collective sentiments into subjugation; actions once considered "blameworthy" are now pardoned in the name of achievement (p. xxxii). The "morality" that results from such a cultural practice "cannot constitute any kind of discipline. The upshot is that the entire sphere of collective life is for the most part removed from the moderating action of any rules" (p. xxxii).

According to Durkheim, since much of the populace is working in an "industrial and commercial environment" lacking in ethics, many people are spending significant periods of their lives "without any moral framework" (p. xxxiv). Because of this, the anomic tendencies so prevalent in economic life cannot help but "spill over beyond the economic sphere, bringing with a decline in public morality" ( $\mathrm{p}$. xxxiv). Though the sphere of trade and industry remain in a state of anomie, Durkheim reminds the reader that this chronic state should not be blamed on the division of labor; a claim that has been unfairly aimed against it (p. xxxiv). This "sorry" state is "abnormal" and, most likely, temporary (although not brief). Nonetheless, Durkheim believes that under anomic conditions (especially in the economic sphere):

those actions most blameworthy are so often excused by success that the boundary between the permissible and the prohibited, between what is just and unjust, is no longer fixed in any way, but seems capable of being shifted by individuals in an almost arbitrary fashion" (p. xxxii). 
Any society operating under these conditions provides an ideal environment for disorder. This ends justifies the means mentality encourages not only corporate and environmental crime, but also social and environmental harms resultant from business practices considered legal. The manufacturing of commodities harmful to those involved in their production or consumption and larger environmental crimes are but a few examples of the conduct that may be excused, ignored or even legitimized if they produce large scale success and monetary reward.

\section{Empirical Tests of Durkheim's Anomie Theory}

Durkheim's theory has been subject to numerous empirical evaluations. Due to the complexity and splintered nature of his theoretical presentation, there has been a great deal of disparity between operational definitions of anomie as well as other pertinent concepts paramount in Durkheim's work. This complexity has also resulted in outright misinterpretation of his overall theory in multiple cases (DiCristina, 2004). While there is a lack of consensus among empirical tests of Durkheim's anomie theory, the previously mentioned complexity of his theory likely has some role in the discrepancy among the empirical findings (Graeff and Mehlkop, 2007).

Crime: In a study evaluating the relationship between a Durkheimian model of the division of labor and international crime rates, Krohn (1978) reported that anomie did not have the expected significance in accounting for rates of international crime. In fact, Krohn reports the amount of variance explained by the model increased when the anomie variable was removed. While anomie did not contribute in accounting for the variance in international crime rates, the author acknowledges that the operationalization of anomie used in this study is "less than adequate" (p. 665) and for this reason the findings are of minimal consequence.

While most empirical studies utilize anomie as an independent variable, Zhao and Cao (2010) treat anomie as a strictly dependent variable in their analysis. Their study produces an anomie score based on respondents' answers concerning "the legitimacy of five instrumental crime-related scenarios" (p. 1217) in countries undergoing various degrees or rates of social change. The sentiment of legitimacy in Zhao and Cao's work appears to be connected most directly with Durkheim's notion of the common consciousness. For societal members to indicate it is acceptable to engage in behaviors of an illegal nature suggests a weakened collective consciousness and therefore an increased state of anomie. Zhao and Cao found that societal members in countries currently undergoing some sort of rapid social change (transitions to democracy) were more likely to offer sentiments more in favor of engaging in illegal behavior. The authors conclude, "rapid social change...elevates the level of anomie among individuals" ( $p$. 1223). These findings offer clear support for Durkheim's theory of anomie. 
A plausible operationalization and test of Durkheim's anomie theory is offered in a series of studies by Pridemore and Kim (2006), Pridemore and Kim (2007) and Pridemore, Chamlin and Cochran (2007). In these works, the authors utilize the natural experiment that was Russian society during the rapid transition in both economic and political systems beginning in the late 1980s and early 1990s. During this time the Russian economy changed from socialist to an open market and their political system from a socialist government to democracy. Concurrent with this rapid transformation these studies found increased rates of homicide, suicide and alcohol related deaths. Pridemore et al. (2007) conclude there was no other "contemporaneous incident" (p. 289) that could account for the increased rates of "deviance" experienced in Russia during this time period.

In their 2006 work, Pridemore and Kim explored change in homicide rates in Russia during Russia's transition from socialism to democracy. The authors maintain this rapid transformation provides an ideal example of an "acute political crisis" which Durkheim believed would produce heightened states of anomie and therefore increased rates of anomic homicide ([1897]1951). This study found that regions in Russia experiencing the greatest degree of political change, as evidenced by decreased support for the former political party, also reported "greater increases in homicide rates" (p. 82) when compared to regions with more homogenous political sentiments. Though the regions with greatest increases in homicide rates were also those with the strongest sentiments towards democracy, Pridemore and Kim do not believe these rates of violence are connected to democracy; rather, "it is the rapid change that appears to be the operative mechanism" (p. 96).

Pridemore and Kim (2007) explored the association between regional homicide rates and rapid "socioeconomic change", operationalized as an index consisting of changes in population, unemployment, privatization and foreign investment. The authors found "higher levels of negative socioeconomic change were positively and significantly associated with greater increases in regional homicide victimization rate" (p. 236). Specifically, the study found regions in Russia that endured the highest rates of unemployment also encountered the highest increases in homicide rate.

Pridemore et al.'s (2007) interrupted time series analysis examines rates of homicide, suicide and alcohol related deaths in Russia between the years 1956-2002. More specifically, the authors' "research, which is also based on Durkheimian thought, seeks to examine the disintegrative effects of rapid social change on the social cohesion of complex social systems" (p. 271); namely, rates of homicide, suicide and alcohol related deaths in early 1990s Russia. Their analysis discovered "significant permanent increases in the level of homicides and alcoholrelated deaths" (p. 284) that are best attributed to the anomic conditions encountered by societal members in a time of political and economic upheaval. The authors conclude with certainty the 
increased rates of "deviant behavior" are associated with the downfall of the Soviet Union and their findings "provide considerable support for Durkheim's deregulation hypothesis" (p. 288).

These studies (Pridemore and Kim 2006; Pridemore and Kim 2007; Pridemore et al. 2007) provide a noteworthy test of Durkheim's anomie theory and results that provide ample support for his theory. They offer support for the idea that rapid change experienced in Russia weakened the "collective consciousness" resulting in increased rates of suicide and homicide "via mechanisms described by Durkheim" (p. 95). Though on a smaller scale, the rapid economic development currently underway in the Bakken Region likewise, may be weakening the regions' collective consciousness resulting in increasing rates of violent crime and suicide.

Suicide: Two cross sectional studies that explore suicide rates and concurrent economic growth with conflicting conclusions are Quinney (1965) and Lester (2001). Quinney's findings support Durkheim's anomie theory. In his investigation of the relationship between economic development and violence (suicide and homicide), Quinney discovered a "fairly constant" linkage existed between the two. Quinney maintains, "suicide is thus a concomitant of structural changes that occur in the process of economic development" (p. 405). Unlike Quinney, Lester found a negative relationship between economic development and rates of suicide across the entire population of his study. The nature of the data utilized for these studies (cross sectional) warrants note as other researchers (Graeff and Mehlkop 2007) call attention to Durkheim's ([1897]1951) position that the effects of anomie on suicide are only noticeable over a period of time; therefore, cross sectional data is not likely to produce the most valid results.

In their analysis of anomic conditions and suicide, Graeff and Mehlkop (2007) explore differences in the geometric mean of Denmark's suicide rates for the years 1945-2005. Their conclusion is a unique one in that they attribute "deviations" of any nature (i.e. increases and decreases $^{5}$ ) from the geometric mean to anomic conditions endured by societal members. The authors conclude, the expansion of economic opportunity during the years 1980-2000 lead to an increase in "deviations" from the geometric mean. This expansion of economic opportunity is akin to the "fortunate crises" Durkheim believed would contribute to increased rates of suicide and deviant behavior.

In her study, Condorelli (2013) offers mixed support for Durkheim's social regulation hypothesis. First, through the utilization of Bayesian analysis, Condorelli offers validation of Durkheim's ([1897]1951) original findings concerning upswings in suicide. In her analysis of the same suicide data utilized by Durkheim ([1897]1951), Condorelli found "The most significant 'waves' of suicide occur exactly when the French sociologist had predicted even by using more rudimentary techniques" (p.1125). However, when Condorelli explored rates of suicide for Italy over the time period 1864-2004 she discovered the data supports Durkheim's theory up to 1961. During this time both suicide rates and industrial growth were steadily 
increasing; however, "Beginning in 1961, in connection to the Italian economic boom, suicide rates decrease, and they do not increase as expected from a Durkheimian theoretical perspective" (p. 1153).

In their respective studies, Minagawa (2012) and Pridemore, Chamlin and Cochran (2007) investigate rates of suicide in regions undergoing the same rapid social and economic change, the collapse of the Soviet Union, and both offer support for Durkheim's theory. Though suicide was not their exclusive focus, Pridemore et al. found an increase in suicide rates that was "dramatic, though short lived" (p. 287). The authors contend the only attributable cause for this spike in suicide are the anomic conditions present at the time of the increase.

Minagawa's investigation of suicide rates in Eastern Europe covered the years 1989-2006, was divided into four time periods (1989-93, 94-98, 99-03 and 04-06) and produced widely varied results for the different time periods. The "rapid and comprehensive structural change" (p. 1049) endured in this region are associated with increased rates of suicide for the first five years of analysis. After this initial time period it appears "the progress in structural reforms benefited population health" (1049) and rates of suicide decreased sharply for every subsequent time period. Initially, the "rapid social change disrupted macro-social order, gave rise to highly anomic conditions and inclined vulnerable individuals toward suicidal behavior" (p.1050-51); however, given time the region appeared to establish new regulatory mechanisms to diminish the heightened state anomie responsible for the spike in suicide.

Minagawa's findings offer support for Durkheim's theory beyond anomie. Durkheim believed that rapid change disruptive to the collective consciousness would result in initial increases in rates of suicide and deviant behavior. Given time though, a society's collective consciousness would recover and develop new regulatory mechanisms that would curb anomic conditions along with the accompanying problematic social issues. In this manner, Minagawa's findings offer support for Durkheim's overall social theory. If Durkheim's theory of anomie is correct and boomtowns also experience increased rates of anomie, we would expect to find within them increased rates of violent crime, suicide and other social ills.

Boomtown Research: The spectrum of ills experienced by boomtowns include, but are not limited to, weakening of informal social controls (Freudenburg 1986; Greider and Krannich 1985a, 1985b), lag in infrastructure and societal institutions (Little 1976; Jacquet 2014; Rudell 2011; Seifert, 2009) increased rates of crime, violence, and child abuse (Cammasso and Wilkinson 1990; Carrington et al. 2011; Freudenburg 1986; Freudenberg and Jones 1991; James \& Smith 2014), difficulties for adolescent populations (Freudenburg, 1984, O’Connor, 2014), suicide (Seydlitz, Laska, Spain, Triche, and Bishop 1993) and public health issues (Goldenberg et al. 2010). Increased rates of crime and victimization are topics boomtown authors have spent a great deal of energy investigating. From the early works concerning boomtowns (Kohrs 1974; 
Little 1976) to the second generation of works analyzed by Freudenburg and Jones (1991) to the later works such as Carrington et al. $(2010 ; 2011)$ and James and Smith (2014), the consensus among these works is that along with increasing rates of extraction activity come increasing rates of violent crime and victimization. Durkheim's theory of anomie provides a lens through which to account for problems encountered by boom communities.

Boomtown research from the 1970s and 1980s concentrated its efforts on the notion of social disruption and the impending social problems experienced in boom communities due to rapid growth and change in socioeconomic conditions. Much of this research was considered to be "anti-growth" (Wilkinson, Thompson, Reynolds, Ostresh 1982) and dismissive of economic benefits; however, this work may be better labeled anti-boom as evidenced by Freudenburg (1979) who noted "there is nothing inherently evil about growth, provided it is a reasonable level of growth" (p. 56). Other authors of this time period echo these beliefs as well, calling for construction and expansion phases to be stretched out over a longer period of time to prevent rapid expansion for which these small communities were unprepared (Little 1976).

Disruptions experienced by communities due to resource booms are the most extensively discussed topic in the boomtown literature. Individual boom communities experience disruptive effects in their own unique manner; however, they all experience disruption in multiple areas (England and Albrecht 1984). Disruption of communal arrangements (i.e. roles and established scripts) among individuals in boomtown settings appears to contribute to uncertainty among community members (Kassover and McKeown 1981) and eventually to further social ills. Summer and Branch (1984) maintain, with rapid expansion comes "general attitudes and values that are uncommon, even unknown, in some localities...that require substantial changes in existing social organization" (p. 148). This need for reorganization of the community serves as a catalyst of constant disruption in these communities. Freudenburg (1984) acknowledges Durkheim's ([1893]1984) notion of anomie and concludes rapid social change can have disruptive effects on individuals' established social patterns, expectations and scripts. In a later work, Freudenburg (1986) maintains evidence of boomtown disruptions is prevalent in the "three functional areas of socialization, deviance control and caring for the community's weaker members" (p. 53).

While the economic benefits of boomtown economies are immediately evident, the social, infrastructural and environmental costs may not be as quickly obvious (Little 1976). As this is the nature of boomtowns, most non-economic issues receive secondary attention resulting in a substantial lag between the communities' needs and the services available (Ruddell 2011). Community institutions often will find themselves in a condition of continually trying to catchup to the boom conditions. Major issues in boomtowns made worse by this lag include, but are not limited to, policing (Ruddell 2011), social services (Camasso and Wilkinson 1990), housing and housing costs (Carrington and Pereira 2011; Jacquet 2014; Little 1976; Seifert 2009), traffic 
and traffic accidents (Seifert 2009) and infrastructure (Braser, Filteau, McLaughlin, Jacquet, Stedman, Kelsey, and Goetz 2011). Even when non-economic issues come to light, it is the community residents who must pay taxes and provide funding for infrastructural needs until (if) policy catches up to the boom growth (Little 1976, Jacquet 2014).

Rates of suicide and mental health/psychological issues among boomtown residents have been analyzed. Multiple authors maintain large scale industrial development has a detrimental effect on the mental health of and psycho-social well-being of community members (Freudenburg, Bacigalupi, Landoll-Young 1982; Jacquet 2014). Also common are findings of increased rates of suicide attempts (Kohrs 1974) and suicide (Seydlitz et al. 1993). These findings seem to reiterate Durkheim's ([1897]1951) warning that "a state of exasperation and irritated weariness" (p.357) in anomic areas exists which contributes to increased rates of suicide and other harmful behaviors.

Issues and concerns that do not affect the direct extraction of resources appear to be often times placed in a position of subjugation due to "orestruck" local leaders and the domineering nature of extraction industries (Carrington et al. 2011; Carrington and Pereira 2011). In other words, non-economic issues within communities are forced into a position of "subjugation" (Carrington et al. 2011). The lag between economic benefits and social costs cultivate an atmosphere heavily focused on short term gratification rather than long term planning. Because of this, extraction industries have been allowed to expand rapidly even though adverse effects have been well documented in previous boom regions (Carrington et al. 2011).

Durkheim's theory of anomie offers a noteworthy lens through which to view the emergent themes in this review of the boomtown literature. The problematic rapid expansion (Little 1976; Freudenburg 1986), disrupted scripts (Freudenburg 1984), lagging institutions (Carrington and Pereira 2011; Jacquet,2014; Ruddell 2011) and subjugation of non-economic issues (Carrington et al. 2011) encountered by these communities and reported in research findings are all issues Durkheim identified with heightened states of anomie. That Durkheim's anomie theory focuses on the detrimental effects of "abrupt growth of power and wealth" ([1897]1951, p. 253) makes it even more applicable to the boomtown literature as well as current circumstances of the Bakken region.

\section{Method}

This study is an exploratory effort examining parallel increases in rates of violent crime and suicide during a time of rapid social change due to the expanding oil extraction industry in the Bakken Region of western North Dakota. North Dakota Attorney General annual crime report data were utilized to compile rates of violent crime (aggravated assault, robbery, forcible rape, and murder/non-negligent manslaughter) for the counties of core economic activity in the 
Bakken Region for the years 2000-2013. These counties' rates were then pooled to create one crime rate for the "Bakken Region" in this study. Crime data for the state of North Dakota as a whole were also taken from the Attorney General's crime report for this same time period to serve as an initial point of comparison. Finally, violent crime rate for North Dakota independent of the Bakken counties was calculated using the same data from the Attorney General's crime report.

Due to confidentiality reasons, suicide data was suppressed and not available for the county level. The only way to access these data were to compile the suicide rate for the Bakken Region comprised of the previously mentioned counties for the years 2004-2013. ${ }^{6}$ Rates of suicide for the state of North Dakota were gathered for the same time period for an initial comparison point. Suicide rates for North Dakota separate of the Bakken Region were configured using data supplied by the North Dakota Department of Health and the same population estimates used in establishing rates of violent crime. Finally, rates of oil production for the Bakken Region were secured from the North Dakota Department of Mineral Resources website with the peak daily oil production by month for each year utilized in the analysis.

Change in rates were calculated by comparing the average rates of violent crime during the pre-boom years 2000-2007 with the years 2008-2013 ${ }^{7}$, with 2008 as a reasonable but albeit arbitrary starting point for the current boom $^{8}$, For suicide, the years 2004-2013 were analyzed with the pre/post boom divide being in $2008^{9}$ as well. While the basis of this comparison is changing crime and suicide rates, multiple authors (Freudenburg 2002; Wilkinson et al. 1982) urge caution with the use of such quantitative data due to small base numbers in many pre-boom communities. While rates and rate changes are used for the purposes of this study, trends in rates of violent crime and suicide are given equal magnitude and attention.

\section{Preliminary Findings}

\section{Violent Crime Rates}

During the post boom years of 2008-2013, the Bakken Region endured an increase in the violent crime rate of $175 \%$ compared to the pre-boom years of 2000-2007. During this same time period the state of North Dakota as a whole sustained an increased in the violent crime rate of 88 percent, (see Table 1). Independent of the Bakken Region, North Dakota experienced an increase in violent crime of 79.6 percent. Not only did the Bakken region experience a greater increase in rate change during this time period, it also surpassed the violent crime rate of North Dakota for the last three years of this analysis in 2011, 2012 and 2013.

The Bakken region saw its average violent crime rate of 71.5 per 100,000 during the preboom years increase to 196.7 during the post boom years; while North Dakota's violent crime 
rate increased from 100 to 188 during this same duration. Meanwhile, North Dakota's violent crime rate independent of the Bakken increased from 101.1 to 181.6. As mentioned earlier, the increase in rates of crime must be interpreted with caution due to the small nature of the initial base numbers. However, the trend that shows these increasing rates of crime possess the most interesting and telling findings (see appendix 1 for graph displaying trends in violent crime rate for the region and North Dakota as well as trends in oil production). In the pre-boom years, the Bakken's violent crime was less than that of the state of North Dakota as a whole. While both the Bakken and North Dakota's violent crime rate increased during the oil boom, the Bakken region surpassed that of North Dakota in 2011 and has widened that difference every year since as oil production continued to increase during these years while accounting for almost $10 \%$ of the overall increase in the state of North Dakota.

\section{Table 1: Violent Crime Rates (per 100,000)}

\begin{tabular}{lcc}
\hline & Pre-Post Boom & Change in Rate \\
\hline Bakken Region & $71.5 / 196.7$ & $+175 \%$ \\
North Dakota & $100 / 188$ & $+88 \%$ \\
North Dakota (without & $101.1 / 181.6$ & $+79.6 \%$ \\
$\quad$ Bakken Region) & & \\
\hline
\end{tabular}

\section{Suicide}

The Bakken region experienced an increase in suicide rate of $106.8 \%$ during the post boom years, while North Dakota as a whole experienced an increase of $16 \%$ during the same time period, (see Table 2). The Bakken region's pre-boom suicide rate average was 10.3 per 100,000 while North Dakota's was 13.8. In the post boom years, the Bakken's average suicide rate increased to 21.3 while North Dakota's increased to 16 (see appendix 1 for graph displaying trends in the suicide rate for the region and North Dakota as well as trends in oil production). The graph in appendix 1 shows the trend for suicide rate in the Bakken region. When configured independent of the Bakken region, North Dakota's pre-boom rate was 14.25 and 14.65 in the post boom years. This increase of 2.8 percent is considerably lower than the increase experienced in the Bakken during the same time period; the Bakken appears to have had a marked influence on North Dakota's overall rate of suicide. In the pre-boom years, the Bakken's suicide rate was less than that of the state of North Dakota as a whole. While both the Bakken and North Dakota's suicide rate increased during the oil boom, the Bakken region surpassed that of North Dakota in 2010 and has widened that difference every year since as oil production continued to increase during these years. In the years prior to the boom (2004-07), the Bakken region reported a suicide rate lower than the state average. In 2008 the suicide rate of the Bakken region surpassed that of the state and was then roughly equivalent in 2009. 
Since 2009 the suicide rate in the Bakken region has surpassed that of North Dakota. While averages were used to determine rate changes, the analysis saw the Bakken region report a suicide rate of 30.7 per 100,000 in the final two years of the analysis, while the state of North Dakota reported rates of 15.9 and 20.5 per 100,000 respectively. The rate of suicide in both the Bakken region and North Dakota are disconcerting when compared with the national average suicide rate during the same time period, which has seen a much smaller increase from -11 to 12.5 per 100,000 (AFSP, 2014).

Table 2: Suicide Rates (per 100,000)

\begin{tabular}{lcc}
\hline & Pre-Post Boom & Change in Rate \\
\hline Bakken Region & $10.3 / 21.3$ & $+106.8 \%$ \\
North Dakota & $13.8 / 16$ & $+16 \%$ \\
North Dakota (without & $14.25 / 14.65$ & $+2.8 \%$ \\
$\quad$ Bakken Region) & & \\
\hline
\end{tabular}

\section{Summary and Discussion}

The current study presented preliminary findings of a larger undertaking exploring rising rates of violent crime and suicide in the Bakken region during a time of rapid economic expansion. Preliminary findings offer support for Durkheim's theory of anomie. The rapid social changes that has accompanied the swift expansion of the oil extraction industry appear to have placed a major burden on pre-existing regulatory mechanisms and rendered them unable to regulate the community in the same manner they did prior to 2007 . The increase in rates of violent crime and suicide were observed to be substantial; however, these numbers must be interpreted with care considering the small base numbers pre-boom (Freudenburg, 1980; Wilkinson et al., 1982). While this caution was exercised, as suggested by Freudenburg (1980), inferences can be made from "general patterns of findings" (p. 4-5) within the Bakken region regardless of rate change. Accordingly, the general patterns discovered are indicative of a region experiencing striking increases in rates of violent crime and suicide concurrent to the massive growth of the oil extraction industry.

Echoing the outcomes of previous authors (Kohrs 1974; Seydlitz et al. 1993), the exploration of suicide rates in the Bakken found a noteworthy increase in an area experiencing rapid economic growth. While North Dakota as a whole has experienced a major increase in suicide rates over the past decade (Daily Mail 2013), the Bakken region has experienced an increase even greater than the state as a whole. The Bakken region's recent increase in suicide rates from 12.8 per 100,000 in the last pre-boom year of 2006 to 30.7 per 100,000 in 2013 
suggests the "fortunate crises" (Durkheim, [1893] 1984, p. 243) of the Bakken region is extolling yet another human toll along with the economic benefits.

The recent economic growth in western North Dakota appears to have brought with it some unintended (yet well documented) social ills. Anomic conditions which Durkheim maintained produce "disorder", "incoherency" and "disintegration" appear to have engendered increased rates of violent crime and suicide in western North Dakota. Durkheim's multiple uses of the term anomie were previously discussed in this article and both offer unique insight into the increased rates of violent crime and suicide encountered in the Bakken region.

In The Division of Labor ([1893]1984), Durkheim maintains anomic conditions impair established scripts created by communities. These scripts provide community members with roles and expectations that guide interactions. The rapid economic growth of the Bakken region arguably has disrupted these scripts and brought with it new conditions of economic life that "naturally require new organization" ([1893]1984, p. 306). The Bakken region appears to find itself in such an environment that requires "new organization". Until the communities in this study are able to establish new scripts for their community, they are at risk of continuing to experience high rates of violent crime.

In Suicide ([1897]1951, Durkheim's theory of anomie focuses on a region's ability, or lack thereof, to regulate the goals and desires of its inhabitants. When properly regulated, the restraint provided by society allows for "calm, active happiness, the pleasure in existing and living which characterizes health for societies as well as for individuals" (p. 250). However, the rapid social change taking place in the Bakken region is a "disturbance of the collective order" (p. 246). Durkheim maintained that this could render regulatory mechanisms impotent. What makes Durkheim's theory even more applicable is his belief that not only "painful crises" may produce detrimental effects, but "beneficent" crises may as well. Durkheim concludes, the "abrupt growth of power and wealth" (p. 254) that accompanies rapid industrialization removed the lid regulating mans' desires in late $19^{\text {th }}$ century France and resulted in heightened states of anomie. It is during these times of heightened anomie "men are more inclined to self-destruction" (p. 246), whether in late $19^{\text {th }}$ century France or the present day Bakken region.

This study extends Durkheim's argument that anomie results in increased rates of suicide and homicide to account for an increase in all levels of violent crime occurring in the Bakken region. While other aspects of Durkheim's theory of anomie may be applicable to the Bakken region (e.g. anomic conditions tendency to "spill over" into areas other than the economic sphere), the core arguments from both The Division of Labor and Suicide provide an impressive lens with which to account for the increased rates of violent crime and suicide the Bakken region has experienced since the rapid expansion of the oil extraction industry began in 2007. Anomic conditions similar to those originally discussed by Durkheim over a century ago likely have 
some role in the increased rates of violent crime and suicide currently occurring in this region. Because of the rapid progression of industry in the Bakken, the region may be unable to provide capable regulatory mechanisms for some time. If this remains the case, the region will likely continue to experience high rates of crime, suicide and other social ills. 


\section{Endnotes}

${ }^{1}$ The Bakken region consists of Dunn, McKenzie, Mountrail, Stark, Ward and Williams Counties. The six counties represent the areas of core economic activity for the oil extraction industry. Dunn County was not utilized in any of these analysis due to missing data for the majority of years of analysis

${ }^{2}$ Durkheim defines the collective consciousness in The Division of Labor as the "totality of beliefs and sentiments common to the average members of a society" (pp.38-39). This serves to produce feelings of solidarity among group members. It is important to note, Durkheim insisted each society produces a common consciousness "sui generis" (of its kind), meaning each society produces its own distinct and unique common consciousness.

${ }^{3}$ According to Durkheim, "the variety of environments in which individuals are placed gives rise among them to different aptitudes that determine their specialization" (p. 206).

${ }^{4}$ A similar sentiment is expressed by Messner and Rosenfeld (2007) in their institutional anomie theory. Messner and Rosenfeld believe all institutions outside the economy have been forced into a role of servitude.

${ }^{5}$ Graeff and Mehlkop (2007) maintain that any deviation from the geometric mean is indicative of anomie. hey argue that "decreasing rates of deviant behavior, therefore, hamper the reinforcement of norms and can reduce the bonding nature of the norm" (p. 526). Durkheim argued that decreased rates of deviant behavior were resultant of an overly repressive collective consciousness which is actually the antithesis of anomie.

${ }^{6}$ Micki Savelkoul's (ND Department of Health) aid in attaining these numbers is greatly appreciated.

${ }^{7}$ State census population estimates were used to calculate the crime rates for the Bakken region and North Dakota. Difficulties establishing a correct population are acknowledged due to the rapid influx of people into the area; however, given the circumstances this "official" estimate was deemed most appropriate if still lacking.

${ }^{8}$ Though the term "post boom" is used in this analysis it is not meant to imply the "boom" occurred and has subsided; rather 2008 is considered to be the initial boom and the following years are considered to be post "initial" boom years.

${ }^{9}$ While drilling for oil began in 2004, there seems to be some disagreement as to when the "boom" actually began in the Bakken. The Oil and Gas Journal designates 2008 as the beginning of the boom. (http://www.ogj.com/articles/print/volume-112/issue-1/explorationdevelopment/bakken-three-forks-largest-continuous-us.html) 


\section{References}

Ag.nd.gov. (2015). Crime homicide reports. Retrieved 5 March 2015, from http://www.ag.nd.gov/Reports/BCIReports/CrimeHomicide/CrimeHomicide.htm

American Foundation for Suicide Prevention,. (2015). American Foundation for Suicide Prevention. Retrieved 5 March 2015, from https://www.afsp.org/

Brasier, K., McLaughlin, D., Rhubart, D., Stedman, R., Filteau, M., \& Jacquet, J. (2013). Research Article: Risk Perceptions of Natural Gas Development in the Marcellus Shale. Envirnomental Practice, 15, 108-122, http://dx.doi.org/10.1017/S1466046613000021

Camasson, M.J. and Wilkinson, K.P. (1990). Severe Child Maltreatment in the Ecological Perspective: The Case of the Western Energy Boomtown. Journal of Social Services Research, 13, 1-18, http://dx.doi.org/10.1300/J079v13n03_01

Carrington, K., and Pereira, M. (2011). Assessing the social impacts of the resources boom on rural communities. Rural Society, 21, 2-20, http://dx.doi.org/10.5172/rsj.2011.21.1.2

Carrington, K., Hogg, R., \& Mcintosh, A. (2011). The resource boom's underbelly: Criminological impacts of mining development. Australian \& New Zealand Journal of Criminology, 44(3), 335-354, http://dx.doi.org/10.1177/0004865811419068

Condorelli, R. (2011). A Bayesian analysis of suicide data. Quality \& Quantity, 47, 1143-1161, http://dx.doi.org/10.1007/s11135-011-9608-9

Daily Mail. (2013). Wyoming and North Dakota top list of States with fastest growing suicide rates. Daily Mail. Retrieved from http://www.dailymail.co.uk/news/article2321733/Wyoming-North-Dakota-list-states-fastest-growing-suicide-rates.html

Davenport, J., III, and Davenport, J. (1980). The boom town: Problems and promises in the energy vortex. University of Wyoming.

Dicristina, B. (2004). Durkheim Theory of Homicide and the Confusion of the Empirical Literature. Theoretical Criminology, 8, 57-91, http://dx.doi.org/10.1177/1362480604039741

Durkheim, E., and Halls, W. D. ([1893]1984). The division of labor in society. NewYork: Free Press.

Durkheim, E. ([1897]1951). Suicide: A study in sociology. Glencoe, IL: Free Press.

England, J., and Albrecht, S. (1984). Boomtowns and social disruptions. Rural Sociology, 49, 230-246. 
Freudenburg, W. R. (1979). An ounce of prevention: Another approach to mitigating the human problems of boomtowns. In Energy resource development: Implications for women and minorities in the Intermountain West (pp. 55-62). Washington, DC: United States Government Printing Office.

Freudenburg, W. (1980). The effects of rapid population growth on the social and personal well being of boomtown residents. In Western Rural Development Center Conference. Scottsdale, AZ.

Freudenburg, W., Bacigalupi, L., and Landoll-Young, C. (1982). Mental health consequences of rapid community frowth: A Report from the longitudinal study of boomtown mental impacts. Journal Of Health And Human Resources Administration, 4, 334-352.

Freudenburg, W. R. (1984). Boomtown's youth: The differential impacts of rapid community Growth on Adolescents and Adults. American Sociological Review, 49, 697-705, http://dx.doi.org/10.2307/2095426

Freudenburg, W. (1986). The density of acquaintanceship: An overlooked variable in community research? American Journal of Sociology, 92, 27-63, http://dx.doi.org/10.1086/228462

Freudenburg, W. R., \& Jones, R. E. (1991). Criminal Behavior and Rapid Community Growth: Examining the Evidence1. Rural Sociology, 56, 619-645, http://dx.doi.org/10.1111/j.1549-0831.1991.tb00449.x

Goldenberg, S., Shoveller, J., Ostry, A., and Koehoorn, M. (2008). Youth sexual behaviour in a boomtown: implications for the control of sexually transmitted infections. Sexually Transmitted Infections, 84, 220-223, http://dx.doi.org/10.1136/sti.2007.027219

Goldenberg, S., Shoveller, J., Koehoorn, M., and Ostry, A. (2010). And they call this progress? Consequences for young people of living and working in resource-extraction communities. Critical Public Health, 20, 157-168, http://dx.doi.org/10.1080/09581590902846102

Graeff, P., and Mehlkop, G. (2007). When Anomie Becomes a Reason for Suicide: A New Macro-sociological Approach in the Durkheimian Tradition. European Sociological Review, 23, 521-535, http://dx.doi.org/10.1093/esr/jcm020

Greider, T., and Krannich, R.S. (1985a). Neighboring Patterns, Social Support, and Rapid Growth: A Comparison Analysis from Three Western Communities. Sociological Perspectives, 28, 51-70, http://dx.doi.org/10.2307/1389074

Greider, T.R., and Krannich, R.S. (1985b). Perceptions of problems in rapid growth and stable communities: A comparative analysis. Community Development Society. Journal, 16, 8096, http://dx.doi.org/10.1080/15575338509490063 
Jacquet, J. (2014). Review of risks to communities from shale energy development. Environmental Science \& Technology, 48, 8321-8333, http://dx.doi.org/10.1021/es404647x

James, A., and Smith, B. (2014.). There will Be blood: Crime rates in shale rich UScounties. Oxcare Research Paper, 1-33.

Kassover, J., and McKeown, R.L. (1981). Resource development, rural communities and rapid growth: Managing social change in the modern boomtown. Minerals and the Environment, 3, 47-54.

Kohrs, E. V. (1974). Social consequences of boom growth in Wyoming. Presented at Rocky Mountain American Association of the Advancement of Science Meeting 1974.

Krohn, M. (1978). A Durkheimian analysis of international crime rates. Social Forces, 57, 654670, http://dx.doi.org/10.1093/sf/57.2.654

Lester, B. (2001). Learnings from Durkheim and beyond: The economy and suicide. Suicide And Life-Threatening Behavior, 31, 15-31.

Little, R. (1976). Some social consequences of boom towns. North Dakota Law Review, 52, 401425.

Mannheim, H. (1972). Pioneers in criminology. Montclair, N.J.: Patterson Smith.

Minagawa, Y. (2012). The social consequences of post-communist structural change: An analysis of suicide trends in Eastern Europe. Social Forces, 91, 1035-1056, http://dx.doi.org/10.1093/sf/sos 172

O'Connor, C. (2012). Agency and reflexivity in boomtown transitions: young people deciding on a school and work direction. Journal Of Education And Work, 27, 372-391, http://dx.doi.org/10.1080/13639080.2012.751093

O'Connor, C. (2015). Insiders and outsiders: social change, deviant others, and sense of community in a boomtown. International Journal Of Comparative And Applied Criminal Justice, 39, 219-238, http://dx.doi.org/10.1080/01924036.2014.973049

Pridemore, W., and Kim S. (2006). Democratization and political change as threats to collective sentiments: Testing Durkheim in Russia. The Annals of The American Academy Of Political And Social Science, 605, 82-103, http://dx.doi.org/10.1177/0002716206286859

Pridemore, W., \& Kim, S. (2007). Socioeconomic change and homicide in a transitional society. The Sociological Quarterly, 48, 229-251, http://dx.doi.org/10.1111/ j.1533-8525.2007.00077.x

Pridemore, W., Chamlin, M., and Cochran, J. (2007). An interrupted time-series analysis of Durkheim's social deregulation thesis: The case of the Russian Federation. Justice Quarterly, 24, 271-290, http://dx.doi.org/10.1080/07418820701294813 
Quinney, R. (1965). Suicide, homicide, and economic development. Social Forces, 43, 401-406, http://dx.doi.org/10.2307/2574770

Ruddell, R. (2011). Boomtown policing: Responding to the dark side of resource development. Policing, 5, 328-342, http://dx.doi.org/10.1093/police/par034

Seifer, L. (2011). A basic analysis of the Bakken oil boom: Precautions and planning.

Seydlitz, R., Laska, S., Spain, D., Triche, E., and Bishop, K. (1993). Development and social problems: The impact of the offshore oil industry on suicide and homicide rates. Rural Sociology, 58, 93-110, http://dx.doi.org/10.1111/j.1549-0831.1993.tb00484.x

Wilkinson, K. P., Thompson, J. G., Reynolds, R. R., and Ostresh, L. M. (1982). Local social disruption and western energy: A critical review, http://Pacific Sociological Review, 25, 275-296.

Zhao, R., and Cao, L. (2010). Social change and anomie: A cross-national study. Social Forces, 88, 1209-1229, http://dx.doi.org/10.1353/sof.0.0312 


\section{Appendix 1}

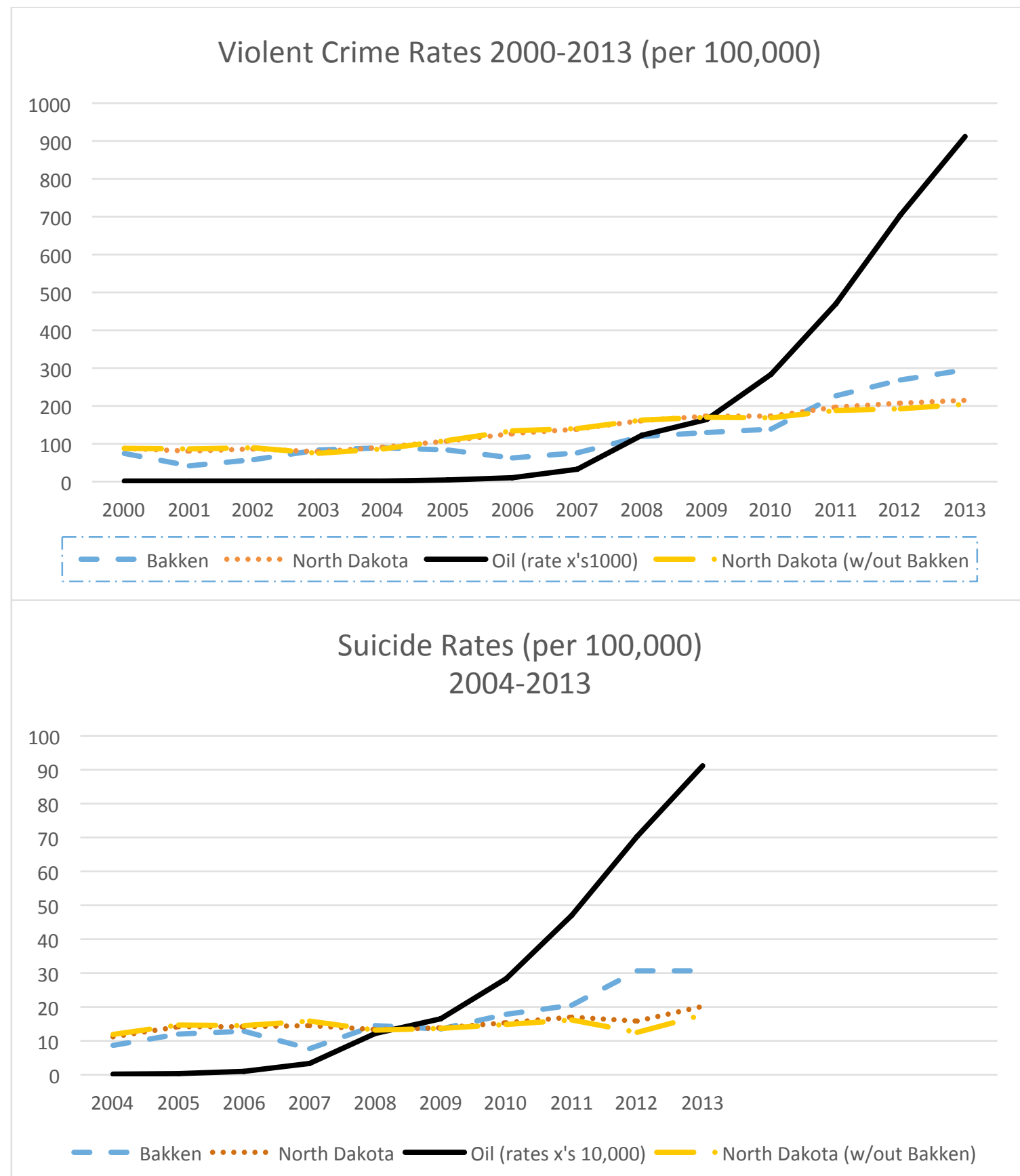

